\title{
dossier
}

\section{Iglesia, guerra y política: \\ el Cabildo Catedral de Puebla ante la intervención francesa (México, 1861-1864)}

\author{
Sergio Rosas \\ Benemérita Universidad Autónoma de Puebla (Puebla, México) \\ sergiofrosas@yahoo.com.mx \\ Código ORCID: 0000-0002-8092-8006
}

\section{RESUMEN}

Este capítulo tiene como objetivo analizar la composición del Cabildo Catedral de Puebla (México), así como su posición política ante la intervención francesa en aquel país entre 1861 y 1864. A partir de la documentación del mismo cuerpo capitular, el trabajo argumenta que, si bien los canónigos estuvieron abiertos a la negociación con las autoridades civiles en el poder, fueran liberales o extranjeras, mantuvieron dos aspectos como la base irrenunciable de su posición pública: la defensa de la posición central del cabildo como autoridad de la ciudad episcopal y la defensa férrea de los bienes eclesiásticos. 
Palabras clave: Cabildo Catedral, diócesis de Puebla, México, intervención francesa, clero

\title{
Church, War and Politics: The Cathedral Chapter of Puebla during the French intervention (Mexico, 1861-1864)
}

\begin{abstract}
This chapter analyzes the composition of the Cathedral Chapter of Puebla (Mexico), as well as its political position during the French intervention in that country between 1861 and 1864. Based on the documentation of the Cathedral Chapter itself, this work argues that even when the canons were open to negotiate with the civil authorities, whether liberal or French, they maintained two aspects as the inalienable basis of their public position: the defense of the central position of the Church as the authority of the clergy and the defense of ecclesiastical properties.
\end{abstract}

Keywords: Cathedral Chapter, Puebla diocese, Mexico, French intervention, clergy

\section{INTRODUCCIÓN}

El OBJETIVO DE ESTE CAPÍTULO ES analizar la composición y la posición política del Cabildo Catedral de Puebla ante la intervención francesa entre 1861 y 1864, un periodo fundamental para (re)definir el papel de la jerarquía eclesiástica ante el poder civil y para que el clero diocesano, encabezado por el cabildo, adecuara su papel social ante la pérdida de espacios políticos y sociales que les produjo la Reforma liberal (Pani, 2013). Así, a partir del caso poblano, quiero contribuir a la historia de las corporaciones catedralicias en el México de la Reforma liberal, analizando la trayectoria, los argumentos y las prácticas políticas de la jerarquía ante la intervención francesa (Thomson, 1999, pp. 239-264). Desde la perspectiva regional, el tema cobra pertinencia a la luz de la historiografía reciente: en un artículo pionero, 
Guy Thomson mostró la preeminencia política del clero en Puebla, así como los vínculos sociales que consiguió tender con los habitantes de la Sierra Norte, una perspectiva reafirmada más tarde desde la óptica diocesana y el ejemplo de Puebla capital (García Ugarte, 2007, pp. 140-168; Tecuanhuey Sandoval, 2011, pp. 199-244). Así pues, este trabajo busca comprender, desde la perspectiva diocesana y regional, el papel de los cabildos en la Reforma liberal.

En esta línea, mi investigación muestra que durante la intervención francesa fue evidente que los canónigos poblanos debieron buscar consensos — no siempre fáciles - para presentar una postura común hacia el exterior, además de mostrar una posición unificada en torno a la posición de la Iglesia en la sociedad. En este artículo me interesa abordar tres elementos: la composición del cuerpo, señalando quiénes eran los canónigos de Puebla durante el periodo; mostrar la posición capitular en torno a los bienes eclesiásticos —una de las principales problemáticas del periodo- y comprender los mecanismos de presencia pública del capítulo en la ciudad. La importancia de tomar Puebla como ejemplo de estudio para entender los cabildos mexicanos es importante, pues se trató de la segunda catedral en importancia de la Nueva España, y mantuvo una gran preeminencia durante la primera mitad del siglo XIX, al ritmo que sus recursos disminuían drásticamente: si en 1795 se habían recaudado 326,937 pesos, en 1810 apenas habían alcanzado 254,357 pesos; en 1833, cuando se canceló la coacción civil del diezmo, se reunieron 102,115 pesos y, finalmente, en 1845 apenas se reunieron 41,995 pesos (Medina Rubio, 1983, p. 196; Cervantes Bello, 1993, p. 194).

Los cabildos catedralicios eran las corporaciones eclesiásticas dedicadas a cuidar el culto en cada catedral, a administrar el diezmo en cada diócesis y a gobernar el obispado en sede vacante. Una característica importante de los cabildos es su permanencia en el tiempo: los canónigos solían permanecer más años que el obispo en una catedral y establecían una tradición diocesana debido al contac- 
to entre los capitulares más antiguos y los recién llegados. En términos canónicos, el cabildo era un cuerpo formado por los clérigos que poseían un oficio dotado con recursos catedralicios obtenidos a través del diezmo, que debían reunirse periódicamente para el gobierno de la catedral y en su caso, de la diócesis; en estas reuniones los capitulares tenían voz y voto. Los cabildos tenían una presencia concentrada en la ciudad episcopal, pues de hecho se trataba de corporaciones eminentemente urbanas y ligadas a su propia catedral (Mazín Gómez, 1996; Pérez Puente, 2005, pp. 363-387). El estudio de los cabildos en la historia de Nueva España (México) no es una temática desconocida. A partir del trabajo pionero de Óscar Mazín, los historiadores han explorado la riqueza de los archivos catedralicios para rescatar la importancia de estas antiguas corporaciones. Durante las dos últimas décadas, las investigaciones han explorado la importancia de los cuerpos capitulares para la conformación de la ciudad episcopal, la relación del cabildo con el obispo a través de aspectos como el diezmo o las estructuras parroquiales, la carrera eclesiástica o la tradición capitular para desarrollar un proyecto diocesano de Iglesia y sociedad que hiciera de los canónigos actores fundamentales de las relaciones religiosas, políticas, sociales y económicas del obispado (Mazín Gómez, 1996; Castillo Flores, 2013). A pesar de esta riqueza temática, los estudios se han concentrado en el periodo virreinal y aún son necesarios estudios más amplios para los siglos XIX y XX. Este capítulo contribuye a subsanar este vacío.

Una perspectiva historiográfica muy sugerente, que se adentra en los primeros años del siglo XIX, es el estudio de la relación entre los cabildos, las estructuras diocesanas y la política. Ana Carolina Ibarra exploró el papel de los canónigos oaxaqueños durante la independencia mexicana. Al hacerlo demostró la importancia de la corporación en el proceso de insurgencia novohispana, gracias a que los canónigos otorgaron un apoyo ambivalente a insurgentes y realistas (Ibarra, 2000). A partir de Ibarra, los historiadores han sido conscientes de que el estudio de los cabildos catedralicios per- 
mite comprender los procesos de cambio político en las sociedades (Jaramillo Magaña, 2014; Pérez Iturbe y Bravo Rubio, 2016). Otras aportaciones han mostrado que los capitulares diseñaron medidas moderadas para conciliar las posturas políticas durante la transición, buscando defender la posición de la Iglesia en la sociedad y buscando mecanismos de administración de la diócesis en los años en que la jerarquía eclesiástica mexicana prácticamente desapareció, en las décadas de 1820 y 1830 (Olveda, 2006, pp. 115-141; Ornelas, 2008 , pp. 403-425). Este capítulo no solo avanza hacia un periodo posterior no estudiado en los cabildos, sino que revela la continua preeminencia de las corporaciones catedralicias durante los años de la Reforma liberal (Rosas Salas, 2012, pp. 15-39).

Así, este trabajo demuestra que entre 1856 y 1863 el Cabildo Catedral de Puebla asumió un papel central en la diócesis como la máxima autoridad eclesiástica presente en el obispado. En mayo de 1856, el obispo Pelagio Antonio de Labastida y Dávalos fue exiliado en Roma por órdenes del presidente Ignacio Comonfort, donde permanecería hasta su regreso en 1863, preconizado ya arzobispo de México. Su estancia en Europa le permitió establecer una relación directa con Pío IX, consolidando no solo su liderazgo en el episcopado sino una férrea posición de defensa de los bienes eclesiásticos. Si bien las consultas entre el mitrado y su cabildo fueron frecuentes, los canónigos asumieron un papel central en el gobierno diocesano, viviendo este periodo como una inédita ausencia episcopal que no era, empero, una sede vacante (García Ugarte, 2010).

Como se demuestra en las líneas siguientes, el periodo que corre de 1861 a 1864 está marcado en el Cabildo de Puebla por el exilio de Pelagio Antonio de Labastida y la llegada a Puebla de su sucesor, Carlos María Colina y Rubio (1863-1878). Este trabajo argumenta que, si bien el obispo Labastida fue, hasta 1864, uno de los principales impulsores de la presencia gala en el país, los canónigos y el obispo Colina pasaron de aceptar la situación como algo dado a ofrecer una discreta resistencia a las medidas impulsadas por la 
Regencia francesa y, más tarde, por la primera etapa del Segundo Imperio. A partir de 1862, incluso, realizaron actos simbólicos en contra del ejército francés - como negar el canto del Te Deum o entierros públicos de las tropas extranjeras-.

Del mismo modo, muestra que, si bien los canónigos estuvieron abiertos a la negociación con las autoridades civiles en el poder, fueran liberales o extranjeras, mantuvieron dos aspectos como la base irrenunciable de su posición pública: la defensa de la posición central del cabildo como autoridad de la ciudad episcopal y la defensa férrea de los bienes eclesiásticos — aspecto, este último, en el que ciertamente coincidieron con el obispo Labastida-. En suma, este capítulo subraya que los canónigos poblanos — como el resto de los actores políticos - mantuvieron una posición pragmática ante el poder civil en aras de defender la posición de la Iglesia en la sociedad. El tercer elemento que se destaca es que los capitulares fomentaron las devociones y la práctica del culto como presencia pública de la corporación. Al hacerlo, subrayaron la religiosidad de la urbe y buscaron mecanismos espirituales para mantener vigente su presencia pública en el contexto de guerra e inestabilidad política que se vivía. De esa manera, este artículo subraya la importancia política, social y religiosa de la corporación eclesiástica durante la intervención francesa en una ciudad episcopal mexicana. En ese sentido, el caso poblano ilustra los debates políticos de la jerarquía eclesiástica mexicana en la época en que esta transitó de la aceptación y aún el apoyo a la presencia extranjera al rechazo a la experiencia imperial, al constatar los afanes liberales de Maximiliano.

\section{Los Canónigos de Puebla en la intervención francesa}

El 19 de abril de 1853, los canónigos de Puebla decidieron reducir los miembros del cabildo de veintisiete a dieciséis miembros, en buena medida debido a la caída en la recaudación decimal 
desde la década de 1830 (Rosas Salas, 2012). ${ }^{1}$ A partir de entonces, el cuerpo estuvo conformado por cinco dignidades — deán, arcediano, chantre, maestrescuelas y tesorero- - un canónigo de oficio -el doctoral_, cuatro canónigos de gracia, tres racioneros y tres medioracioneros. En 1860, sin embargo, se eligió otro canónigo de gracia. $^{2}$ A pesar de que no se desatendieron las cuestiones urgentes del gobierno capitular y aún las reuniones fueron constantes, los años de la Reforma liberal están marcados por la muerte de varios capitulares, la mayor parte de los cuales tenía más de veinte años de servicio. La pérdida más importante fue la de Ángel Alonso y Pantiga, fallecido el 12 de febrero de 1859, y quien había ejercido un importante liderazgo desde su nombramiento en 1814 como canónigo de gracia, llegando incluso a gobernar dos veces el obispado. ${ }^{3}$ Ante su fallecimiento, el cabildo quedó conformado por apenas once miembros (véase el cuadro 1). Del mismo modo, entre 1859 y 1860, murieron otros dos capitulares: el maestrescuela José Antonio de Haro y Tamaríz y el chantre José Camilo Jiménez. En consecuencia, el cabildo quedó presidido, al iniciar la década de 1860, por el arcediano José Pedro de Echávarri, quien poseía la dignidad más alta de la corporación. Ante esta renovación generacional, el doctoral Francisco Suárez Peredo, uno de los recién llegados, empezó a construir un nuevo liderazgo, que se consolidó cuando fue elegido gobernador de la mitra en 1864.

1 Como parte de la primera reforma liberal, en 1833, el vicepresidente Valentín Gómez Farías decretó el fin de la coacción civil en el pago de diezmos, que nunca volvió a restituirse.

2 Archivo del Cabildo Catedral de Puebla (en adelante, ACCP), Actas de Cabildo, libro 66, f. 335; ACCP, Borradores de Actas Capitulares, legado del 9 de enero de 1852 al 19 de abril de 1853, f. s.n. Cabildo del 19 de abril de 1853.

3 Archivo General de Indias (en adelante, AGI), Audiencia de México, 2655. 
Cuadro 1. Miembros del Cabildo Catedral en 1860

\begin{tabular}{|c|c|}
\hline Posición & Nombre \\
\hline Arcediano & José Pedro de Echávarri \\
\hline Tesorero & José Francisco Yrigoyen \\
\hline Doctoral & Francisco Suárez Peredo \\
\hline Canónigo & Miguel María de Iturriaga \\
\hline Canónigo & José Antonio Reyero \\
\hline Canónigo & José Francisco Serrano \\
\hline Canónigo & Miguel María de Iturriaga \\
\hline Canónigo & Manuel Ladrón de Guevara \\
\hline Canónigo & Ambrosio López del Castillo \\
\hline Canónigo & Eusebio Espetillo \\
\hline Racionero & José Simón Quiróz \\
\hline
\end{tabular}

Fuente: ACCP, Actas de Cabildo, libros 68 y 69, 1859-1860.

¿Cuál era el perfil de las dos generaciones de canónigos que convivían en la catedral de Puebla al iniciar la década de 1860? La primera estaba conformada por los capitulares más antiguos, quienes habían llegado al cabildo hacia 1831. Se trataba de clérigos formados en la última década de 1790, estudiantes en los años de la insurgencia novohispana y párrocos en los primeros años de la independencia. Formaron parte de la generación de canónigos llegados a las catedrales durante la primera república federal. Los representantes más importantes de esta generación fueron José Pedro de Echávarri, José Francisco Yrigoyen y Manuel Ladrón de Guevara. La trayectoria del primero de ellos es el ejemplo clásico de las carreras capitulares de la primera mitad del siglo XIX: Echávarri nació en la Angelópolis el 29 de abril de 1787 y cursó sus estudios en el Seminario Palafoxiano, doctorándose en teología en la Universidad 
de México. En el Colegio de San Juan —uno de los integrantes del Palafoxiano- dictó las cátedras de Filosofía y Lugares Teológicos, antes de obtener en 1809 una beca en el Colegio de San Pablo, el mayor de la diócesis y semillero de la alta jerarquía poblana. Después de su ordenación, en 1818, se dedicó a servir como director espiritual en Puebla, encargado de múltiples novenarios y sermones, pero sobre todo dedicado a encabezar las conferencias morales del clero en la Mansión Clerical de San Juan Nepomuceno (Echávarri, 1831, pp. 1-3). Si bien no atendió alguna parroquia — como ocurría con varios de sus contemporáneos-, su trayectoria como estudiante, colegial de San Pablo, catedrático, director espiritual y orador le daba cartas sólidas para aspirar a una silla capitular. En consecuencia, Echávarri tomó un asiento en el cabildo el 29 de octubre de 1831, y llegó a ser arcediano siguiendo un riguroso escalafón.

Lo mismo ocurría con José Francisco Yrigoyen, quien dictó la cátedra de Filosofía en el Colegio de San Juan en 1829, y con Ladrón de Guevara, quien en 1831 dictó Sagrados Cánones, después de haber obtenido el bachillerato por la Universidad de México y ser colegial de San Pablo desde 1829. Los últimos miembros de esta generación morirían durante la intervención francesa: el 25 de abril de 1861 murió Miguel María de Yturriaga, y el 27 de enero de 1862 falleció el arcediano José Pedro de Echávarri. Desde 1860 habían expirado José Antonio Reyero y José Francisco Serrano. Por último, en 1864 fenecieron Eusebio Espetillo, Juan Nepomuceno Ortega y José Simón Quiróz, este último ascendido el 17 de agosto de $1863 .^{5}$ Ello llevó a que en 1864 el cabildo tuviera apenas cinco miembros.

4 La misma trayectoria siguió José Antonio de Haro, hermano del ministro santanista y general conservador Antonio de Haro y Tamaríz, quien, como hemos visto, murió en 1859. Biblioteca Palafoxiana (en adelante, BP), R-493. Expedientes de oposición de méritos, ff. 34, 163.

5 ACCP, Actas de Cabildo, libros 67-69, passim. 
Estas muertes obligaron a los capitulares a iniciar una lenta renovación generacional, que no se había concretado la década anterior debido a los escasos ingresos. El primer paso fue ascender a los miembros existentes en 1860. El 16 de julio se eligieron tres canónigos de gracia y un racionero; también se ascendió a Eusebio Espetillo, Mariano Ladrón de Guevara y Antonio López de Castillo a canónigos, y a José Simón Quiróz a racionero. Así, el cabildo quedó integrado por once miembros: dos dignidades, siete canónigos y un racionero. Quedaron vacantes cinco posiciones, que no se cubrieron por la escasez de rentas eclesiásticas. ${ }^{6}$ Así, pues, la problemática decimal de la diócesis —agravada por la guerra de los Tres Años, recién concluida - había reducido el cabildo a once miembros, el número acordado en 1853. Pero no habían tocado fondo. Como ya hemos dicho, a fines de 1864 el capítulo poblano tenía apenas cinco canónigos: José Francisco Yrigoyen, Francisco Suárez Peredo, Manuel Ladrón de Guevara, Ambrosio López del Castillo y José Simón Quiróz, quien se encontraba gravemente enfermo. Ello obligó a una nueva renovación aquel año. Entonces, los cambios se dieron en dos sentidos: se ascendió en el escalafón capitular a los miembros, y se admitió al interior del cuerpo a los sacerdotes diocesanos de carrera más destacada. Ya bajo el obispado de Carlos María Colina y Rubio —quien llegó a Puebla el 7 de febrero de 1864-, el 16 de abril se eligieron deán, arcediano y chantre, así como tres canonjías de gracia, tres raciones y tres medias raciones. ${ }^{7}$ El 22 de abril de 1864, por fin, se reorganizó el cabildo, conformado con doce miembros (véase el cuadro 2). ${ }^{8}$

6 ACCP, Actas de Cabildo, libro 69, ff. 81v-82. Sesión del 18 de agosto de 1863.

7 ACCP, Actas de Cabildo, libro 69, f. 113. Acta del 5 de febrero de 1864.

8 ACCP, Actas de Cabildo, libro 69, f. 121v. Acta del 22 de abril de 1864. 
Cuadro 2. Miembros del Cabildo Catedral en 1864

\begin{tabular}{|c|c|}
\hline Posición & Nombre \\
\hline Deán & José Francisco Yrigoyen \\
\hline Arcediano & Ambrosio López del Castillo \\
\hline Chantre & José Simón Quiróz \\
\hline Doctoral & Francisco Suárez Peredo \\
\hline Canónigo & Manuel Ladrón de Guevara \\
\hline Canónigo & Felipe de Jesús Rodríguez \\
\hline Canónigo & Mateo Rebolledo \\
\hline Racionero & Francisco Javier Miranda \\
\hline Racionero & Juan Francisco Cabañas \\
\hline Medio racionero & Ramón Vargas \\
\hline Medio racionero & Juan José Otero \\
\hline Medio racionero & José María Mora \\
\hline
\end{tabular}

Fuente: ACCP, Actas de Cabildo, libro 69, f. 121.

Si bien con estos cambios el liderazgo seguía ejercido por José Francisco Yrigoyen, el miembro más antiguo, ya para 1864 los canónigos poblanos no formaban parte de la primera generación de capitulares mexicanos. A pesar de que compartían algunos rasgos con ellos — como la trayectoria escolar y sacerdotal—, habían vivido otro periodo en la historia del país, marcado por un creciente conflicto entre Iglesia y Estado. A ello hay que sumar que estos nuevos capitulares dirigirían una corporación en crisis, con recursos prácticamente inexistentes: en 1864, por ejemplo, las dignidades ganaban setenta pesos anuales, los canónigos recibían cincuenta y los racioneros y medioracioneros treinta. ${ }^{9}$ Esta generación de cabildantes daría un perfil especial al cabildo en los años de la intervención

9 ACCP, Actas de Cabildo, libro 68, f. 121. 
francesa, y aún en el Segundo Imperio y la República Restaurada, periodo aún por explorar. Los casos de Ambrosio López del Castillo, Francisco Suárez Peredo y Ramón Vargas son los más interesantes.

Suárez Peredo, el doctoral, era miembro de una familia notable de Orizaba. Llegó a Puebla en 1835 para estudiar en el Seminario Palafoxiano; en 1837 obtuvo el bachillerato en Filosofía por la Universidad de México y, a partir de entonces, se dedicó al estudio del derecho. En 1839 enseñaba Derecho Natural en la diócesis de Puebla, y dos años después alcanzó el bachillerato en Cánones, con base en el cual pudo ser admitido como colegial de Derecho en el Eximio Colegio de San Pablo. Enseñó mínimos en San Juan y, en 1843, fue nombrado miembro del Colegio de Abogados de la ciudad de Puebla. En 1849 se tituló de abogado y, a partir de entonces, sirvió como párroco interino de Orizaba, después de haber sido promotor fiscal cinco años. Ingresó al cabildo en 1852, siendo uno de los pocos ingresos de aquella década. ${ }^{10}$ Como se ve, era un experto en ambos derechos y, desde los últimos meses del gobierno de Francisco Pablo Vázquez, había defendido desde los Cánones y el Derecho la posición de la Iglesia en momentos tan álgidos como 1847.

Otros dos capitulares venían de la Sierra Norte de Puebla, semillero de varios capitulares y aún de un obispo - Ambrosio María Serrano, primer mitrado de Chilapa - en los años de la Reforma. El arcedeán Ambrosio López del Castillo fue cura de Tlatlauquitepec desde 1831 hasta 1853, cuando fue nombrado racionero de la catedral. Como las trayectorias de Antiguo Régimen, destacó por haber mejorado el templo, los caminos y el abasto del agua y, en fin, por servir espiritualmente en momentos difíciles como la epidemia de cólera de 1833 (Torre Villar, 2006, pp. 125-131). Esta labor era especialmente importante en la Sierra, uno de los centros de liberalis-

10 BP, R-532. «Méritos y ejercicios literarios de Don Francisco Suárez Peredo», ff. 298-300v. 
mo popular más radicales desde la década de 1840; gracias a él, Tlatlauqui fue un centro de apoyo a la Iglesia en la región (Thomson, 2010). Una trayectoria similar siguió su discípulo Ramón Vargas, uno de los llegados al cabildo en 1864. Contemporáneo de Suárez Peredo, estudió en el Seminario Palafoxiano a partir de 1833, y en 1841 entró al servicio de sus cátedras. ${ }^{11}$ Entre 1849 y 1854 fue párroco de Coscomatepec y Acatzingo, y el último año fue nombrado sucesor de López del Castillo como cura de Tlatlauquitepec. Ocupaba esta posición cuando fue nombrado medioracionero.

Como se ve, las dignidades y los recién llegados al cabildo tenían amplia trayectoria educativa y pastoral. Mientras los primeros coronaban una trayectoria iniciada en la década de 1840, los nuevos miembros tenían una sólida formación en el Seminario Palafoxiano, grados académicos y servicio como curas en parroquias importantes de la ciudad. ¿En dónde radicaba entonces lo novedoso? En los años de su formación y servicio. Suárez Peredo y Vargas López, por señalar los casos más destacados, se formaron en la década de 1830, marcada por la primera reforma liberal del vicepresidente Valentín Gómez Farías, y sirvieron en las parroquias después de la guerra con los Estados Unidos, en un periodo que sirvió como fermento ideológico de los radicalismos políticos que, finalmente, se enfrentarían en la Reforma liberal (Fowler, 2016, pp. 15-36). Así, pues, la intervención francesa encontró en Puebla un cabildo mermado, con apenas once miembros, pero integrado por canónigos que destacaban por su perfil regional, por su trabajo pastoral previo y, lo más importante, por haberse formado y servido en un periodo marcado por crecientes conflictos entre ambas potestades y el fortalecimiento del liberalismo en el país. Sus antecedentes en la defensa de la posición de la Iglesia, pues, marcarían el derrotero de la corporación en los años por venir, y los prepararían para el liderazgo diocesano

11 BP, R-532. «Méritos y ejercicios literarios del Presbítero Don Ramón Vargas López, como consta de los documentos que obran en esta Secretaría», ff. 265-267. 
que debieron enfrentar ante la falta del obispo en los días en que llegaron las primeras tropas francesas a México.

\section{ENTRE LA SUPERVIVENCIA Y LOS BIENES ECLESIÁSTICOS}

Hay dos elementos que marcaron la relación del Cabildo de Puebla con el gobierno civil, primero con el régimen de Benito Juárez y, más tarde, con el ejército galo: la amenaza de la extinción legal del cuerpo según la legislación liberal y la defensa de los bienes eclesiásticos. Los canónigos dejaron claro que, más allá de los cambios de gobierno, la jerarquía poblana defendía la exclusiva jurisdicción del clero sobre los asuntos de potestad eclesiástica - como eran, desde la óptica capitular, el gobierno de la diócesis y la propiedad de los bienes espiritualizados-.

En el marco de las Leyes de Reforma, expedidas por el gobierno liberal el 12 y 13 de julio de 1859 y que declararon la independencia entre Iglesia y Estado, una primera preocupación del cabildo era la extinción legal de la corporación. Impulsado a una posición radical por la guerra, el gobierno de Benito Juárez — recién victorioso en la Guerra de los Tres Años- amenazó a los cabildos catedralicios con su supresión, una medida complementaria a la expulsión de la mayor parte de los obispos del país, cuyo objetivo era desplazar del gobierno de la Iglesia a una jerarquía eclesiástica acusada de haber apoyado al régimen de Tacubaya. El 15 de enero de 1861, el tesorero poblano José Francisco Yrigoyen informó a sus colegas que el «decreto de extinción de cabildos» estaba en prensa, por lo que debía prepararse un plan de acción en caso de su promulgación. ${ }^{12}$ La base sería la misma que se había expresado ya desde 1859: que la potestad eclesiástica era independiente del poder civil. Los canónigos creían que, a pesar de enunciarlo así, el gobierno de

12 ACCP, Actas de Cabildo, libro 69, ff. 4-5v. Sesión del 17 de enero de 1861. 
Juárez no cumplía con este objetivo, pues invadía la jurisdicción exclusiva de la Iglesia. Esta tesis fue expuesta por José Francisco Yrigoyen en su protesta contra las Leyes de Reforma en julio de 1859. En aquel documento sostuvo que la Iglesia era una «sociedad santa que Jesucristo estableció en el mundo, como sociedad perfectamente constituida, y a la cual, por lo mismo, dio el poder, el imperio sobre todos sus súbditos, aunque sean Soberanos» en cualquier aspecto espiritual (Protesta,1859, p. 4).

Con base en esta posición, expresada ya en 1859, el doctoral Francisco Suárez Peredo preparó la representación del cabildo en caso de su extinción. Sus propuestas muestran una continuidad en la postura capitular ante la Reforma, e ilustran cuáles eran las ideas que los canónigos tenían de su propia labor. Los primeros puntos del dictamen de Suárez Peredo establecían que, además de protestar contra la decisión del gobierno, se evitaría el rezo de las horas canónicas fuera de la catedral y el cese de las misas rezadas. ${ }^{13}$ Los siguientes tres apartados se referían a la situación económica: el gasto de los instrumentos para el culto se haría con las reservas de la catedral —que en 1861 ascendieron a 97 pesos, pues se recibieron 28,212 pesos y se erogaron 28,115 - y los últimos cinco puntos se refirieron al manejo de los bienes a cargo del cabildo, desde la mesa capitular hasta el hospital de San Pedro y el Seminario Palafoxiano. ${ }^{14}$ Desde la perspectiva del doctoral, la corporación debía hacer público su rechazo a la legislación liberal, pero su principal preocupación debía ser mantener vigentes el culto y el gobierno capitular sobre los elementos de la jurisdicción eclesiástica. En conjunto, pues, los canónigos asumieron tres tareas básicas: el cuidado del culto divino — que era, según el derecho eclesiástico, su principal tarea—, la administración de los diezmos y la defensa de los bienes eclesiásticos.

13 ACCP, Actas de Cabildo, libro 69, f. 4v. Sesión del 17 de enero de 1861.

14 ACCP, Actas de Cabildo, libro 69, ff. 4v-5v. El cálculo de los recursos catedralicios se encuentra en f. 43. 
El elemento fundamental del quehacer del cuerpo durante este periodo fue la defensa de los bienes eclesiásticos. Como en el caso anterior, la base inmediata de su postura era la representación de 1859, aunque su defensa tenía una ya amplia tradición a lo largo del siglo XIX. En palabras de José Francisco Yrigoyen, los bienes de la Iglesia eran defendidos no solo por interés, sino porque a través de ellos se guardaba «la sagrada independencia y soberanía de la Iglesia». Si el régimen de Juárez y el cabildo coincidían en la búsqueda de independencia entre ambas potestades, ¿en qué radicaba el conflicto? En que desde la perspectiva del tesorero no se le reconocía independencia a la Iglesia «en lo puramente eclesiástico», como las propiedades y los registros vitales (Protesta, 1859, pp. 12-13). Esta fue la premisa de la posición capitular: que los bienes eclesiásticos eran propiedad y jurisdicción exclusiva de la potestad de la Iglesia, y esta autoridad estaba respaldada por las propias Leyes de Reforma y protegidas, por tanto, por el propio régimen liberal.

En este aspecto, el cabildo siguió la misma línea que el obispo Labastida: defendió los bienes de la Iglesia como elementos sujetos solo a la jurisdicción de la jerarquía eclesiástica y sometidos, por tanto, tan solo a las decisiones de los obispos y/o cabildos. Ya el general Bazaine informó a Napoleón III en París que, al volver al país, el recién preconizado arzobispo Labastida, en octubre de 1863, defendía las «ideas... del clero romano, que son casi las del clero español del tiempo de Felipe IV, excepción hecha de la Inquisición»y, por lo tanto, no sería posible encontrar una conciliación en el tema de las propiedades eclesiásticas, a pesar de las (falsas) esperanzas de Almonte. ${ }^{15} \mathrm{~A}$ fines de aquel octubre, incluso, el general francés informó a Labastida que no podría establecer ninguna ne-

15 «Minuta de carta del General Bazaine al Ministro de la Guerra francés, en que le informó del Estado de defensa de México y le transmitió las noticias recibidas acerca del Ejército republicano» y «Copia de carta del General Bazaine al Emperador Napoleón III, sobre la conducta de la Regencia, del Señor de Saligny y del Mariscal Bazaine», en García (2012, pp. 119, 145). 
gociación con él, pues no estaba autorizado para ello. ${ }^{16}$ La postura de Labastida ciertamente se había visto fortalecida al volver como arzobispo, pero no era nueva. La ratificó en varias ocasiones ante los capitulares poblanos y, de hecho, el cabildo emprendió algunas acciones para defender y aún recuperar bienes de la iglesia de Puebla. El 29 de enero de 1861, por ejemplo, Suárez Peredo se entrevistó con el gobernador liberal Juan Bautista Traconis para solicitar la devolución del Palacio Episcopal y, a pesar de que se enteró en la misma reunión de que el gobierno tomaría control del seminario, consiguió que el 22 de abril el inmueble le fuera devuelto por órdenes del presidente Juárez, con la garantía de que no sería afectado el inmueble educativo. Aún más: en un intento por acercarse a la jerarquía eclesiástica, el presidente Juárez ordenó el 22 de abril que el Palacio Episcopal fuera devuelto al cabildo, y le garantizó que podría mantener el edificio del seminario. ${ }^{17}$ Hechos como estos muestran la política pragmática de Juárez, fundamental para evitar mayores confrontaciones en vísperas de la intervención (Hamnett, 2006).

El cabildo mantuvo la misma posición frente a las autoridades francesas. A pesar de que no hubo un enfrentamiento directo por los bienes, sí hubo expresiones evidentes de la postura capitular. Así, por ejemplo, el 21 de agosto de 1863, Suárez Peredo informó a sus compañeros que Juan N. Almonte, líder de la Regencia tras la renuncia de Labastida, estaba molesto con los canónigos poblanos porque tenía noticias de que «por parte del clero se están recogiendo firmas para una representación que se quería hacer para que se devolviesen los bienes eclesiásticos». ${ }^{18}$ Así, pues,

16 «Copia de comunicación del General Bazaine al Ministro de Negocios Extranjeros francés, con informes sobre los puertos de Tampico y Matamoros, sobre la ayuda que él prestaba a los americanos del sur y sobre las ideas del Arzobispo Labastida», en García (2012, pp. 164-165).

17 ACCP, Actas de Cabildo, libro 69, ff. 13-20.

18 ACCP, Actas de Cabildo, libro 69, f. 82. 
es evidente que el cabildo mantuvo la defensa de los bienes y, por tanto, defendió la jurisdicción eclesiástica a pesar de las variaciones en el régimen político.

Lo mismo ocurrió en los primeros años del Segundo Imperio, si bien entonces los capitulares no tuvieron el mismo éxito que al negociar con Juárez respecto al Palacio Episcopal. El 29 de julio de 1864, el cabildo fue demandado por José María Luna por la deuda de pan del hospital de San Pedro, bajo cuidado capitular desde su fundación en el siglo XVI. A pesar de la insistencia de los capitulares de que el pago se hacía por años vencidos, Luna amenazó con recurrir al gobierno imperial. ${ }^{19}$ Los meses siguientes mostraron que aquel no era sino el principio de un embate gubernamental por hacerse de la administración del inmueble y, más, de la institución hospitalaria. Si bien esto se concretó hasta la República Restaurada, entre 1864 y 1865 la defensa de San Pedro ocupó buena parte del tiempo del Cabildo. El 18 de noviembre de 1864, el Comisario Imperial informó a Juan Francisco Cabañas que el emperador no quería hacerse del hospital, sino supervisar su correcto funcionamiento, pero al mismo tiempo estipuló que el cabildo debía estar presto para rendir cualquier información al régimen. ${ }^{20}$ Preocupados más por negociar que por abrir un enfrentamiento que debió parecerles estéril en vista de la postura liberal del gobierno de Maximiliano, el 25 de enero de 1865 el cabildo acordó suspender cualquier inversión en el hospital, que por lo demás estaba desde la década de 1850 en manos de las Hermanas de la Caridad. ${ }^{21}$ Asimismo, se suspendieron las plazas de contador y administrador de San Pedro, pues consideraban que era mejor alejarse de la administración del

19 ACCP, Actas de Cabildo, libro 69, f. 137.

20 ACCP, Actas de Cabildo, libro 69, f. $163 \mathrm{v}$.

21 Hay varios trabajos sobre la posición liberal del II Imperio a partir del problema eclesiástico, como Galeana de Valadés (1991), Pani (2001) y Ratz (2008, pp. 141-157). 
hospital, ya que el estar en manos de religiosas — sin que por ello renunciaran a su titularidad y patrocinio- lo haría menos vulnerable a la intervención estatal. ${ }^{22}$

Estos ejemplos muestran que además de su propia supervivencia, la principal preocupación del Cabildo Catedral fue la defensa de los bienes eclesiásticos. Como en el caso de las previsiones a tomar ante la posible extinción del cuerpo, el doctoral Francisco Suárez Peredo tuvo un papel importante en las negociaciones con el poder civil. ${ }^{23} \mathrm{Al}$ repasar la actuación de 1861 y 1864 en defensa del Palacio Episcopal y del hospital de San Pedro, los miembros del cabildo se revelaron como actores dispuestos a dialogar con cualquier gobierno constituido, pero con base en una premisa básica: que los bienes eclesiásticos eran propiedad y jurisdicción exclusiva de las autoridades de la Iglesia. Si para los canónigos la desamortización era una medida casi natural de Juárez, que el Segundo Imperio mantuviera la misma posición les fue más difícil de entender. Como ocurrió con el caso del obispo de Michoacán Clemente de Jesús Munguía, en Roma, la posición liberal de Maximiliano — visible en su posición ante los bienes - estuvo en la base de la ruptura de la jerarquía eclesiástica con el gobierno imperial (Mijangos y González, 2015). En Puebla, el cabildo había dejado claro, desde su protesta de 1859, que defenderían a los que juzgaban la jurisdicción exclusiva de la Iglesia, como la posesión y administración de bienes, y de hecho esta fue su posición invariable durante la intervención francesa. Estos debates, empero, no eran tan visibles como los que se vivieron en torno a la presencia del ejército francés en Puebla.

\section{ACCP, Actas de Cabildo, libro 69, f. 175.}

23 No hay que perder de vista que el doctoral era el encargado de la defensa legal del cabildo, por lo que su papel también está determinado por su propia posición capitular. 


\section{LOS FRANCESES EN LA CATEDRAL: CULTO DIVINO Y PRESENCIA PÚBLICA}

El 8 de enero de 1861, el Cabildo de Puebla salió de la ciudad a recibir a Juárez; dos años después, en 1863, recibió en la catedral al triunfante general Forey, «le ofreció agua bendita y lo condujo al lugar que se le había reservado en el coro», a pesar de que en torno al recinto se había instalado «un vasto reducto protegido por una doble hilera de barricadas», que dificultaban el culto público y hacían evidente la presencia de la guerra en la ciudad (Ollivier, 2012, pp. 86-111). Ambas ceremonias muestran la postura capitular de reconocer a cualquier gobierno, así como la importancia que los actores políticos otorgaban a ser reconocidos y recibidos por el cabildo catedralicio; finalmente, subrayan la importancia de las ceremonias públicas en la ciudad episcopal. En ese sentido, el otro elemento que interesa subrayar en estas líneas es la presencia pública de los capitulares en los años de la intervención.

El primer aspecto público del cabildo era la administración del culto. Sin duda, fue uno de los aspectos más afectados por el contexto bélico; al tiempo que los canónigos evitaban salir de la ciudad episcopal, ocupaban el espacio público para impetrar la paz. Unos días antes de la batalla de Puebla, el 29 de abril de 1862, el cabildo acordó cantar misa en la catedral por la festividad de San Miguel del Milagro, toda vez que era imposible viajar hasta su santuario en el valle de Natívitas, como se hacía usualmente. El 12 de mayo se acordó festejar a San Juan Nepomuceno, pidiendo por las necesidades de Puebla, en una ceremonia catedralicia pública. El 17 de junio se insistió en «que aumentándose cada día más las necesidades, y temiéndose que la ciudad, sufra un ataque en el que los males serían incalculables, pedía se mandasen decir al Señor San Juan N. nueve Misas rezadas, para que como Patrono del Cabildo y el Clero nos 
libre de los males de que estamos amenazados». ${ }^{24} \mathrm{~A}$ instancias del canónigo Juan Nepomuceno Ortega, el 12 de agosto se acordó celebrar veinticinco misas rezadas por «los peligros que nos amenaza la guerra... para que Dios Nuestro Señor nos libre de esos males». Aún el 30 de mayo de 1863, el doctoral Suárez Peredo insistió al cabildo que debían mantenerse «la salve y letanía que se cantaba diariamente por las necesidades, [dado] que estas no habían terminado, y podían considerarse mayores hasta el término de la revolución». El 1 de marzo de 1864, en fin, el cabildo acordó celebrar una misa a la Divina Misericordia «para que cese la calamidad de los enfermos de tifo, que es ya epidemia aunque no se haya declarado». ${ }^{25}$ En conjunto, estos ejemplos muestran que los canónigos respondieron a la situación de guerra con lo que consideraban su mayor obligación canónica: la promoción y el mantenimiento del culto divino en la ciudad episcopal. De nueva cuenta, estos ejemplos muestran una posición pragmática del cabildo ante los gobiernos civiles en aras de mantener un bien mayor: la permanencia del culto divino en la medida de lo posible, y la impetración por las necesidades de la Iglesia y de la ciudad. Para los canónigos, la vida devocional era una labor fundamental en la difícil situación que enfrentaba la ciudad, máxime en un contexto de guerra que, como bien ha mostrado Francisco Javier Cervantes Bello (2005, pp. 287-306), devastó no solo los templos, sino al conjunto de la urbe. Era la mejor manera que tenían los canónigos para defender a la ciudad de los avatares de las acciones bélicas.

Si la relación del Cabildo Catedral de Puebla con los actores políticos fue pragmática en virtud de la defensa de los bienes eclesiásticos y la vida devocional, el trato con las tropas francesas entre 1861 y 1864 y el Segundo Imperio durante 1864, y aún en 1865, muestra, en la misma lógica, una paulatina separación de intereses

24 ACCP, Actas de Cabildo, libro 69, f. 56v.

25 ACCP, Actas de Cabildo, libro 69, ff. 59, 65, 116. 
entre el poder extranjero y los canónigos, que va de la aceptación de la presencia gala como algo dado hasta el rechazo simbólico de la presencia del emperador, producto final de la presencia francesa en la ciudad y el país. En ese sentido, a través del cuerpo capitular angelopolitano, se hace evidente la separación entre las fuerzas extranjeras y la Iglesia católica mexicana por su desacuerdo en torno a la posesión de bienes eclesiásticos, lo que a la postre privó al Imperio de uno de sus apoyos más importantes.

En el seno del Cabildo Catedral de Puebla, las relaciones con el poder civil fueron dirigidas primordialmente por el doctoral Francisco Suárez Peredo, quien ya entonces era el primer obispo electo de Veracruz. Frente a la historiografía oficial que ha señalado a Francisco Javier Miranda como la pieza clave de enlace entre el alto clero poblano y el ejército francés o el Imperio en Puebla, las actas muestran que el doctoral fue el interlocutor del cuerpo capitular con el poder civil, gracias al respaldo que el obispo Pelagio Antonio de Labastida y Dávalos le otorgó, al grado de nombrarlo gobernador de la mitra. Ello, por supuesto, no niega que desde 1860 y hasta su muerte en 1863, Miranda hizo presentes las peticiones del ejército francés e, incluso, del emperador ante el alto clero poblano. Sin embargo, si bien Miranda fue elegido como canónigo, no tomó posesión de su prebenda por morir a los pocos meses. Ajeno así al cabildo, su papel en él fue más bien marginal; era ante todo un portavoz. Empero, alejado del trajín político secular, Suárez Peredo fomentó una relación cordial con el ejército francés, asumiendo que, desde mayo de 1863, era dueño de la plaza y como debía ser reconocido por el cabildo. Sin embargo, los cabildantes evitaron hacer un reconocimiento oficial de la Intervención, incluso si el ya arzobispo Labastida y Dávalos fue en 1863, por algunos meses, el presidente de la Regencia gubernativa. En este punto sí hubo posturas divergentes entre el cabildo y el obispo, a diferencia de lo ocurrido con los bienes eclesiásticos.

El primer encuentro directo de los capitulares con el ejército 
francés fue el 25 de mayo de 1863. Suárez Peredo informó al cuerpo que esa mañana se había presentado «un capellán del General Forey» para «decir Misa en esta Santa Yglesia». Según dijo, se le pidió ajustar la celebración a la hora de los oficios, «aún con algún descomedimiento». Rechazado por el doctoral, más tarde volvió otro eclesiástico francés, «con más moderación». A solicitud del obispo electo de Veracruz, el cuerpo eclesiástico decidió «en atención a las circunstancias... se adelanten las horas y Misa Conventual a las siete para que quede espedita la Yglesia para la hora en que concurran [los militares franceses]». ${ }^{26}$ Unos días más tarde, el 13 de junio, los canónigos se negaron a firmar el acta de adhesión al Imperio que preparaba el Ayuntamiento. Para evitar un desaguisado, aceptaron cantar un Te Deum a petición de los regidores, siempre y cuando ellos mismos pagaran la función, como de hecho hicieron. ${ }^{27}$

El 16 de junio de 1863, los canónigos celebraron una función a San Juan Nepomuceno por el término de la guerra, trayendo a la catedral la imagen de Nuestra Señora de la Soledad. Asumida la victoria gala, el 3 de julio Suárez Peredo firmó un acta de reconocimiento al Imperio y, al día siguiente, se entonó un Te Deum por la nueva monarquía mexicana, a petición expresa y con el patrocinio del Ayuntamiento. Aún el 17 y el 22 de julio se cantaron un par de Te Deum por la proclamación del emperador Maximiliano. El 10 de agosto de 1863 se cantó uno más, esta vez por el ejército francés. ${ }^{28}$ Esta conducta muestra que el Cabildo Catedral de Puebla no otorgó apoyo directo al ejército francés a pesar de su presencia militar, sino que lo aceptó como autoridad legítima una vez tomada la ciudad. Del mismo modo, los capitulares solo reconocieron al Imperio cuando había llegado el emperador, manteniendo la posición de reconocer solo a las autoridades constituidas. Así, se puede

\footnotetext{
26 ACCP, Actas de Cabildo, libro 69, f. 64v.

27 ACCP, Actas de Cabildo, libro 69, f. 67.

28 ACCP, Actas de Cabildo, libro 69, ff. 67v-79.
} 
aseverar que, en sus relaciones con el poder civil, aleccionado ya por la experiencia de más de cuarenta años de vida independiente e inestabilidad política, el cabildo catedralicio no militó activamente con ningún bando político, sino que reconoció a quien detentaba el poder en la ciudad. Al hacerlo, ciertamente, le otorgó legitimidad ante el resto de la población al hacer visible su adhesión. Pragmático, el cabildo aceptó a tirios y troyanos como había aceptado a la república en 1861, «en atención a las circunstancias». Por ello, por ejemplo, aceptó cantar un Te Deum para Forey y más tarde para Maximiliano. De hecho, el cuerpo capitular es más pragmático que partidario de la intervención, como sostuvo Emilio Ollivier y repitió la historiografía liberal casi desde el momento mismo de los acontecimientos. Por otra parte, los ejemplos muestran el liderazgo que Francisco Suárez Peredo había alcanzado en las relaciones del cabildo poblano con el poder civil, una constante hasta su partida a Veracruz en mayo de 1864.

Pero la avenencia con el nuevo régimen tenía sus límites. Así como el reconocimiento público era evidente con las ceremonias públicas, los Te Deum y aún las procesiones, el rechazo a las decisiones de gobierno también fue evidente a través de gestos simbólicos que, al hacerse públicos, enviaban muestras inequívocas de la posición de los capitulares, amén de expresarse como un debate directo con las autoridades. El 21 de agosto de 1863, por ejemplo, el doctoral informó al cabildo que Juan N. Almonte disputaba la posición capitular sobre sus propiedades, y estaba molesto con los canónigos porque «no se había iluminado la catedral la noche del día 15 ni adornado el Palacio Episcopal», cuando Maximiliano entró a México. ${ }^{29} \mathrm{El}$ hecho de no haber festejado la llegada del nuevo soberano era una muestra inequívoca de rechazo, que incomodó al regente en tanto hacía pública la imposibilidad de alcanzar apoyos en torno al Imperio. El rechazo a la presencia francesa e imperial

29 ACCP, Actas de Cabildo, libro 69, f. 82. 
—en buena medida como resultado de la postura liberal de Maximiliano- siguió haciéndose evidente en pequeños actos simbólicos. El 13 de octubre, el cabildo aceptó celebrar en la catedral un funeral a «un general francés», cuyo nombre no se especifica, pero con la condición de hacerlo «en lo privado» y sin llamar la atención del público. Como en pocas ocasiones, fue evidente a los miembros de la milicia francesa que, detrás de esta simbólica hostilidad, estaba la molestia capitular a las disposiciones del recién llegado Aquiles Bazaine, quien tenía órdenes de Napoleón III para reconocer la venta de bienes eclesiásticos (Dabbs, 2012).

El rechazo a la política liberal de los franceses se hizo extensivo a Maximiliano y, en general, al Segundo Imperio. El 22 de enero de 1864, el canónigo Juan Francisco Cabañas informó que el gobierno del Estado había solicitado el Palacio Episcopal para que ahí descansara el emperador. Cabañas respondió que no podía prestarlo, pues estaba próximo a llegar el obispo Carlos María Colina y Rubio. En el cabildo de aquel día, «el Señor Doctoral dijo que aprobaba la resolución. Y el señor Ortega dijo que no sólo aprobaba la resolución, sino que a nombre del Cabildo daba las gracias». ${ }^{30}$ Dos semanas después llegó el obispo Colina y, el 7 de mayo de aquel 1864, murió Francisco Javier Miranda. Perdido el principal contacto de Francia y el Imperio con el alto clero poblano, y teniendo un obispo con quien dialogar — que, sin embargo, tampoco apoyó la intervención-, el cabildo perdió protagonismo en la relación con el poder civil. Cuando el nuevo obispo escribió por primera vez a los capitulares desde Guatemala, les reconoció haber defendido a la Iglesia poblana en medio de «las muchas dificultades de que hoy la considero rodeada», por «el desquiciamiento más completo y universal que la Religión y la Yglesia han sufrido dolorosísimamente en México, junto con la persecución más deshecha que ha habido contra Dios y su culto, contra las cosas santas y sus Ministros, y por

30 ACCP, Actas de Cabildo, libro 69, f. 87v. 
añadidura también la más tiránica explotación de todos sus bienes, recursos y emolumentos». Les agradeció, finalmente, haber llevado a lo largo de estos años un «buen gobierno espiritual, y exacta dirección en el orden religioso y canónico». ${ }^{31}$

Como puede colegirse, sin renunciar a una postura pragmática que garantizara la defensa de sus posturas más preciadas, el cabildo aceptó en un primer momento la intervención extranjera como un hecho dado, como había hecho con el resto de los gobiernos que habían podido dominar la ciudad. Sin embargo, la aquiescencia de los capitulares poblanos con el régimen no era absoluta: estaba marcada por el respeto que debía el gobierno civil a los bienes de la Iglesia católica. Cuando Bazaine, y más tarde el emperador Maximiliano, suscribieron la política liberal en torno a los bienes eclesiásticos iniciada por el gobierno de Ignacio Comonfort en 1856, la aceptación del cabildo al nuevo régimen dio paso a un rechazo a la intervención extranjera que fue suscrita por el obispo Carlos María Colina.

\section{Conclusiones}

Entre 1861 y 1864, el Cabildo Catedral de Puebla vio morir a varios de sus miembros, lo que lo llevó a un relevo generacional que permitió su renovación durante la intervención francesa, y que permitió que convivieran en la catedral dos generaciones de capitulares que compartían su origen diocesano, su formación en el Seminario Palafoxiano y, en menor medida, su servicio pastoral. Los capitulares más antiguos, quienes habían ingresado en las décadas de 1840 y 1850, enfrentaron entonces una situación inédita en el país debido a la expulsión de México de Pelagio Antonio de Labastida y Dávalos

31 ACCP, Correspondencia del Obispo Carlos María Colina con este Cabildo, f. s/n. De Carlos María Obispo de Puebla al Presidente y Cabildo de la Diócesis de Puebla, Guatemala, 18 de mayo de 1863, f. 3v. 
en 1856: la necesidad de gobernar a la diócesis de Puebla sin el obispo, sin que la ausencia episcopal significara que había sede vacante. Ello produjo que el cabildo tomara el mando del obispado, y dio a los canónigos y, aún más, al doctoral Francisco Suárez Peredo, un protagonismo que le permitió no solo gobernar la diócesis, sino negociar la posición de la Iglesia de Puebla con el gobierno juarista, el ejército francés y el emperador Maximiliano, las autoridades constituidas que fueron reconocidas por el cabildo una vez que se habían hecho del poder — como solían hacer con cualquier autoridad desde la independencia-.

El Cabildo Catedral de Puebla concentró su actividad pública y política en torno a tres problemáticas: la amenaza de extinción legal del cuerpo por parte del gobierno liberal, la defensa de los bienes eclesiásticos y la conformación de una presencia pública que, centrada en la vida devocional, respondiera a la continua situación de guerra. En el primer rubro, la propuesta de Suárez Peredo, compartida por el resto de los canónigos, subrayó que el cabildo asumía como sus tareas principales el cuidado y conservación del culto divino, la administración de los bienes eclesiásticos y, más aún, su defensa. Así, la premisa básica de los capitulares respecto a este tenor fue que los bienes eclesiásticos eran de exclusiva competencia eclesiástica. Al sostener este argumento, los clérigos retomaron la postura expresada por el tesorero Yrigoyen en 1859: que la defensa de sus bienes era, en realidad, una defensa de la independencia de la Iglesia frente al poder civil, tal como habían planteado las Leyes de Reforma. Esta convergencia con Juárez tenía como objetivo defender la posición de la Iglesia en la sociedad, lo cual impelía a los capitulares a defender los bienes diocesanos.

En suma, vale la pena insistir, la defensa de sus bienes es el elemento fundamental para comprender la posición política del Cabildo Catedral de Puebla. El hecho de que para Maximiliano fuera una concesión real y para los canónigos un derecho inherente a la soberanía de la Iglesia católica condenó a ambos actores a un divor- 
cio que, a la postre, haría infructuosa la estancia del ejército francés en México y condenaría al joven emperador a vivir una tragedia de sobra conocida. Al defender los bienes eclesiásticos, el Cabildo de Puebla aparece como un actor pragmático — como el resto de los actores políticos de los años de la Reforma- que aceptó al gobierno dominante en aras de defender un elemento que no estaba dispuesto a negociar. Cuando el régimen extranjero no garantizó su devolución o al menos su no injerencia —algo que el mismo régimen de Juárez sí había hecho, al devolver en 1861 el Palacio Episcopal—, los canónigos pasaron de la aceptación al rechazo. Este se expresó, sobre todo, a través de prácticas devocionales que mostraron a la ciudad el cuidado del cabildo sobre su ciudad episcopal, y su interés en fomentar el culto divino a pesar de las circunstancias bélicas. El culto era una necesidad y una muestra de la presencia del cabildo en la ciudad. Había, por supuesto, otros elementos simbólicos. De hecho, que Maximiliano no pudiera dormir en el palacio que esperaba al obispo Carlos María Colina fue la muestra simbólica de un rompimiento que empezó antes que el mismo Imperio, en los años de la intervención francesa aquí analizada, en actos como negar a «un general francés», sin nombre conocido, un entierro público en la catedral de Puebla.

\section{REFERENCIAS}

ArChIVOS Y BIBLIOTECAS DE FONDO ANTIGUO

Archivo del Cabildo Catedral de Puebla [ACCP]

Archivo General de Indias [AGI]

Biblioteca Palafoxiana [BP]

\section{FUENTES IMPRESAS}

EchávarRi, José Pedro de (1831). [Relación de Méritos]. Puebla, Imprenta del hospital de San Pedro.

GARCíA, Genaro (compilador y traductor) (2012). La intervención francesa en 
México según el archivo del Mariscal Bazaine, tomo I, Puebla, Secretaría de Educación Pública del Estado de Puebla, El Colegio de Puebla.

Protesta del Ilustrísimo y Venerable Señor Presidente y Cabildo de la Santa Iglesia Catedral de la Puebla, contra el manifiesto y decretos publicados en Veracruz en julio del presente año (1859). Puebla, Imprenta de Rivera.

\section{Bibliografía}

Castillo Flores, José Gabino (2013). «La Catedral de México y su Cabildo eclesiástico, 1530-1612». Tesis de doctorado. Zamora: El Colegio de Michoacán.

Cervantes Bello, Francisco Javier (1993). «De la impiedad y la usura. Los capitales eclesiásticos y el crédito en Puebla (1825-1863)». Tesis de doctorado. México: El Colegio de México.

Cervantes Bello, Francisco Javier (2005). «Guerra e Iglesia en Puebla, 17801863». En: Anne Staples (coord.). Bienes y vivencias. El siglo XIX, volumen IV, en: Pilar Gonzalbo Aizpuru (dir.). Historia de la vida cotidiana en México. México: El Colegio de México; Fondo de Cultura Económica, pp. 287-306.

DABBS, Jack Autrey (2012). El ejército francés en México, 1861-1867. Estudio del gobierno militar. Puebla: Secretaría de Educación Pública del Estado de Puebla; El Colegio de Puebla.

Fowler, Will (2016). «El México de los años de la intervención estadounidense y la posguerra (1846-1856)». En: Raymond Buve y Romana Falcón (coords.). El México profundo en la gran década de desesperanza (1846-1856). México: Benemérita Universidad Autónoma de Puebla; Instituto de Ciencias Sociales y Humanidades «Alfonso Vélez Pliego»; Ediciones de Educación y Cultura, pp. 15-36.

Galeana de Valadés, Patricia (1991). Las relaciones iglesia-estado durante el Segundo Imperio. México: Universidad Nacional Autónoma de México, Instituto de Investigaciones Históricas.

García Ugarte, Marta Eugenia (2007). «Church and State in Conflict: Bishop Labastida in Puebla, 1855-1856». En: Susan Dean-Smith y 
Eric Van Young (eds.). Mexican soundings. Essays in honour of David A. Brading. Londres: Institute for the Study of the Americas, University of London, pp. 140-168.

García Ugarte, Marta Eugenia (2010). Poder político y religioso en México. Siglo XIX. México: Miguel Ángel Porrúa; Universidad Nacional Autónoma de México; Instituto de Investigaciones Sociales; Cámara de Diputados.

Hamnett, Brian (2006). Juárez: El benemérito de las Américas. México: Colofón.

Ibarra, Ana Carolina (2000). El Cabildo Catedral de Antequera, Oaxaca y el movimiento insurgente. Zamora: El Colegio de Michoacán.

Jaramillo Magaña, Juvenal (2014). Una elite eclesiástica en tiempos de crisis. Los capitulares y el Cabildo Catedral de Valladolid-Morelia (1790-1833). Zamora: El Colegio de Michoacán, Instituto Nacional de Antropología e Historia.

Mazín Gómez, Óscar (1996). El Cabildo Catedral de Valladolid de Michoacán. Zamora: El Colegio de Michoacán.

Medina Rubio, Arístides (1983). La Iglesia y la producción agrícola en Puebla, 1540-1795. México: El Colegio de México.

Mijangos y González, Pablo (2015). The Lanyer of the Church: Bishop Clemente de Jesús Munguia and the Clerical Response to the Mexican Liberal Reforma. Lincoln: University of Nebraska Press.

Ollivier, Emile (2012). La Intervención Francesa y el Imperio de Maximiliano en México. Puebla: Secretaría de Educación Pública del Estado de Puebla, El Colegio de Puebla.

Olveda, Jaime (2006). «El Cabildo eclesiástico y los liberales: élites en conflicto, 1821-1831». En: Jaime Olveda, Guadalajara. Abasto, religión y empresarios. Guadalajara: El Colegio de Jalisco, Instituto Cultural Ignacio Dávila Garibi, pp. 115-141. 
Ornelas, Moisés (2008). «El Cabildo eclesiástico en sede vacante y los conflictos locales con el poder civil: el obispado de Michoacán, 18211831». En: Francisco Javier Cervantes Bello, Alicia Tecuanhuey y María del Pilar Martínez López Cano (coords.). Poder civil y catolicismo en México, siglos XVI al XX. México: Benemérita Universidad Autónoma de Puebla; Instituto de Ciencias Sociales y Humanidades «Alfonso Vélez Pliego»; Universidad Nacional Autónoma de México, Instituto de Investigaciones Históricas, pp. 403-425.

PANI, Erika (2001). Para mexicanizar el Segundo Imperio. El imaginario politico de los imperialistas. México: El Colegio de México; Instituto Mora.

PANI, Erika (2013). Una serie de admirables acontecimientos. México y el mundo en la época de la Reforma, 1848-1867. Puebla: Benemérita Universidad Autónoma de Puebla; Ediciones de Educación y Cultura.

Pérez Iturbe, Marco Antonio y Berenise Bravo Rubio (2016). «Patronato y redes imperiales: el cabildo eclesiástico de México, 1803-1821». En: Leticia Pérez Puente y José Gabino Castillo Flores (coords.). Poder y privilegio: cabildos eclesiásticos en Nueva España, siglos XVI a $X I X$. México: Instituto de Investigaciones sobre la Universidad y la Educación; Universidad Nacional Autónoma de México; pp. 303-323.

Pérez Puente, Leticia (2005). «El poder de la norma. Los cabildos catedralicios en la legislación concilian». En: Pilar Martínez López Cano y Francisco Javier Cervantes Bello (coords.). Los concilios provinciales en Nueva España: reflexiones e influencias. México: Universidad Nacional Autónoma de México, Instituto de Investigaciones Históricas, Benemérita Universidad Autónoma de Puebla, Instituto de Ciencias Sociales y Humanidades «Alfonso Vélez Pliego», pp. 363-387.

RATZ, Konrad (2008). Tras las huellas de un desconocido: nuevos datos y aspectos de Maximiliano de Habsburgo. México: Siglo XXI editores.

Rosas Salas, Sergio (2012). «La provisión del Cabildo Catedral de Puebla, 1831-1835». Secuencia, núm. 84, pp. 15-39. 
Tecuanhuey Sandoval, Alicia (2011). «Antes del conflicto general: Puebla, 1855-1860». En: Brian Connaughton (coord.). México durante la Guerra de Reforma, tomo 1: Iglesia, religión y leyes de reforma. Xalapa: Universidad Veracruzana, pp. 199-244.

Thomson, Guy P. C. (1999). «La contrarreforma en Puebla, 1854-1867». En: Will Fowler y Humberto Morales Moreno (coords.). El conservadurismo mexicano en el siglo XIX. Puebla: Benemérita Universidad Autónoma de Puebla; Saint-Andrews University; Gobierno del Estado de Puebla, pp. 239-264.

Thomson, Guy P. C. (2010). La Sierra de Puebla en la política mexicana del siglo XIX. Puebla: Benemérita Universidad Autónoma de Puebla, Ediciones de Educación y Cultura.

Torre Villar, Ernesto de la (2006). Diario de un cura de pueblo y relación de los señores curas que han servido la parroquia de Nuestra Señora de la Asunción de Tlatlauqui, escrita por el Señor Cura Don Ramón Vargas López. México: Secretaría de Cultura de Puebla, Universidad de las Américas de Puebla, Consejo Nacional para la Cultura y las Artes, Universidad Nacional Autónoma de México.

Fecha de recepción: 23 de noviembre de 2020.

Fecha de evaluación: 12 de febrero de 2021.

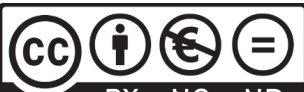

Fecha de aceptación: 6 de abril de 2021.

Fecha de publicación: 1 de noviembre de 2021. 